\title{
Untangle Multi-Organizational Collaboration From Value Co-creation
}

\author{
Shih-Chieh Fang ${ }^{1} \&$ Dan-Wei Wen ${ }^{1}$ \\ ${ }^{1}$ Department of Business Administration, National Cheng Kung University, Taiwan \\ Correspondence: Dan-Wei Wen, Department of Business Administration, National Cheng Kung University, Taiwan.
}

Received: July 18, 2018

doi:10.5430/ijba.v9n5p76

\begin{abstract}
Multi-organizational collaboration is a major method for firms to jointly create value. But received research from the value-based view puts much more emphasis on value capture over value creation among organizations. This research adopts value co-creation perspective from service science to propose a framework to address (1) the variety of value that can be created, and (2) key factors making multiple organizations co-create value. Theoretically, this paper provides a potential solution to untangle success factors of multi-organizational collaborations. Specifically, value co-creation perspective opens an alternative lens to investigate why organizations collaborate when they are not controlled by organizational hierarchy. Practically, this paper reflects how collaborations with other organizations could be evaluated from a non-competition-oriented manner to achieve better collaboration performance.
\end{abstract}

Keywords: value co-creation, multi-organization collaborations, unity, shared goal, sustainability

\section{Introduction}

Multi-organizational collaborations have served as strategic means for firms to achieve competitive advantages. Through collaborating with other organizations, firms get access to important complementary resources (Dyer \& Singh, 1998), explore new markets or technologies (Pitelis, 2012), and enhance business potentials (Brandenburger \& Stuart, 1996; Chang \& Chen, 2016; Chatain, 2011; Möller \& Svahn, 2006; Mindruta, 2013; Obloj \& Zemsky, 2015; Tantalo \& Priem, 2016; Xia, Zhao, \& Mahoney, 2012). From the value-based perspective, multi-organizational collaborations create value by collective efforts. However, extent research puts far more emphasis on value capture than value creation while they are at least equally salient (Chatain \& Zemsky, 2011; Obloj \& Zemsky, 2015).

This paper re-accentuates value creation in business strategy studies by explicitly focusing on why multiple organizations in the collaboration system jointly create a variety of value. Rooted in the multi-organizational context, this paper lay emphasis on joint effort in creating value. Furthermore, a variety of value has been discovered in organizational collaborations, this paper tackles the variety from two distinctive dimensions that have been discussed in literature.

In this vein, this paper adopts value co-creation from Service Dominant Logic (SDL) (Vargo \& Lusch, 2016; Vargo, Maglio, \& Akaka, 2008), which accentuates creating value with customers, instead of for customers, and redefines value from customers' view. SDL, which makes value co-creation one of the theoretical cornerstones, has proliferated in recent decades (Lambert \& Enz, 2012; Ranjan \& Read, 2016; Vargo \& Lusch, 2016). Value co-creation mainly delves into how end users of products or services take up more active roles in the design and production phases so that participants in the collaboration enjoy both value-in-exchange and value-in-use (Payne, Storbacka, \& Frow, 2008). In a word, this paper attempts to extract the inherent themes of value co-creation and map them to multi-organizational collaborations: autonomous organizations, organic system, shared goal, and economic and non-economic benefits.

The autonomous organizations in the collaboration system are organizations that are not linked by authoritarian relationships (Alstyne, Parker, \& Choudary, 2016; Gulati, Puranam, \& Tushman, 2012) so that resources and capabilities can be integrated beyond the boundaries among multiple organizations in (Fjeldstad, Snow, Miles, \& Lettl, 2012; Möller \& Svahn, 2006). Without the authoritarian bonding, these organizations share equity (Ranjan \& Read, 2016). These organizations intertwined into a networked system (Marcos-Cuevas, Nätti, Palo, \& Baumann, 2016; Ranjan \& Read, 2016) that may grow or decline with respect to the number of organizations in the collaboration system (Gulati, Wohlgezogen, \& Zhelyazkov, 2012; Tomasello, Napoletano, Garas, \& Schweitzer, 2016). The value co-creation system exists due to the pursuit of a shared goal among the organizations in the 
collaboration system that may be too difficult to achieve for individual one (Xia et al., 2012). The results of value co-creation activities include economic benefits, such as market expansion (Pitelis, 2012), and non-economic benefits, such as experience, relationship and learning (Aoki \& Lennerfors, 2013; Ranjan \& Read, 2016; Xia et al., 2012) for both the system and participating organizations. After clarifying the concepts and core elements of value co-creation strategy, this paper proposes a conceptual framework together with propositions for future research.

The theoretical contributions include: (1) elucidating value co-creation in the multi-organization collaboration context, (2) explicating the wisdom of value co-creation consideration in the strategy field, and (3) providing one possible solution to the long-standing puzzle on achieving collaborative success. In management practice, this paper sheds light on emerging phenomena (i.e., sharing economy and platform revolution) and parses the mechanisms that make these new business arrangements work.

\section{Literature Review}

\subsection{Value and Multi-Lateral Relationships in Organizational Collaborations}

Multi-organizational collaborations proliferate in recent years as a critical means to solve complex social and economic issues (Koschmann, Kuhn, \& Pfarrer, 2012). Different groups of collaborating organizations may have different purposes, functions, duration and management mechanisms (Olk \& Young, 1997), but there is fundamentally at least one common pursuit within a group. Under a macroscopic view, this paper discusses overarching issues of why multiple organizations collaborate and temporarily neglect their subtle differences.

One prominent yet not fully answered question surrounds the essence of value created form these multi-organizational collaborations. Branstetter and Sakakibara 2002) discover that the performance of multi-organizational collaboration is determined by potential R\&D spillover and members' product market competitions in government-sponsored R\&D consortia in Japan. However, Olk and Young (1997) suggest that there are positive and negative outcomes in multi-organizational collaborations, and the performance of the entire collaboration affects the continuity of members. Moreover, Xia et al. (2012) argue that organizational learning and social capital should be included as two kinds of value. As the literature suggests, the determinants and measurements of consortia performance need further clarification. Such scholarly discussions take place regarding alliances, joint ventures and merge and acquisitions as well.

To delve deeper into why multi-organizational collaborations generate value, one key premise lies in having a holistic view on the inter-organizational relationships. Received literature has provided ample insights into the bilateral relationships within the multi-organizational collaborations, but less is discussed about multi-lateral relationships (Tomasello et al., 2016). Studies into multi-later relationships are emerging, for example, Fonti, Maoret, and Whitbred (2017) conceptually theorize how the focal firm's evaluation of other members in a consortium would affect the collaboration and also implement the survey of cross evaluation of multiple organizations in the collaboration system to accentuate the fact that more than two members affect the potential performance of a consortium.

Value-based strategies have attracted much discussion since late 1990's (Brandenburger \& Stuart, 1996), and scholars point out that the essence of strategy study lies in the creation and capture of value, and how firms enhance themselves upon the basis of the concept of value (Mahoney \& Qian, 2013; Pitelis \& Teece, 2009). In a word, value-based business strategy delves into how the focal firm adds value to the product or service along the value chain, draw resources from the value system, and thus capture value (Brandenburger \& Stuart, 1996; Chatain, 2011; Chatain \& Zemsky, 2011).

However, even though both value creation and value capture are important elements in value-based approach, received literature has largely stressed value capture to the detriment of value creation. Most literature either investigate how firms capture more value (Obloj \& Zemsky, 2015) or how value creation affects value capture (Chatain, 2011; Obloj \& Zemsky, 2015). Such imbalance significantly hinders strategy research and practice from the broader picture of generating more appropriable value (Vakili, 2016). As well put by Normann and Ramirez (1993) that "strategy is the art of creating value Normann and Ramirez (1993) p.65," and re-asserted by Vakili (2016) that value creation are the antecedents of value capture, this paper follows such call to accentuate value creation.

Moreover, as pointed out by Brandenburger \& Stuart (1996) that value is "created by firms together with their suppliers and buyers (p. 5)," this paper focuses on how the focal organization works "with" other organizations as a response to the initial call for unveiling value-based strategies, thus adopts value co-creation to further investigate the dynamic and system-oriented perspective (Kohtamäki \& Rajala, 2016) of value creation dynamics. 


\subsection{Value Co-creation in Multi-Organizational Collaboration}

Value co-creation is an emerging topic in service science, arguing that end users of products or services take up more active roles in the designing, manufacturing and marketing of the products or services by joining the processes (Alves, Fernandes, \& Raposo, 2016; Galvagno \& Dalli, 2014; Ind \& Coates, 2013; Kohtamäki \& Rajala, 2016; Marcos-Cuevas et al., 2016; Payne et al., 2008; Ranjan \& Read, 2016; Vargo et al., 2008).

Value co-creation brings refreshing ideas on the essence of value (Ramaswamy \& Ozcan, 2014; Ramírez, 1999; Vargo et al., 2008). In the multi-organizational context, value is conventionally defined as "what customers are willing to pay" (Porter, 1985:3), and is extended in the value co-creation literature to include value-in-use (Kohtamäki \& Rajala, 2016; Ranjan \& Read, 2016; Vargo et al., 2008). In another word, the benefits derived from the offerings include the economic aspects from the exchange, such as revenue, as well as the non-economic ones from using the offerings, such as knowledge sharing, equity, interaction, experience, personalization, and relationship (Ranjan \& Read, 2016). Moreover, in the multi-organizational relationships, value is augmented by incorporating organizational learning and social capital (Kohtamäki \& Rajala, 2016; Xia et al., 2012).

Besides, distinctive boundaries between suppliers and customers, as defined in conventional value chain, become less apparent since customers are integrated into the boundary of an organization as co-creators (Ramaswamy \& Ozcan, 2014). Meanwhile, the dominant role of the firm in the production processes yields to the role as a manager of the co-creation ecosystem (Ramaswamy \& Gouillart, 2010). In another word, value co-creation accentuates the integration of producers and users of offerings thus generate value for the organizations in the collaboration system through interaction.

In the strategy field, however, value co-creation is rarely explicitly discussed (Galvagno \& Dalli, 2014), but to be left scattering in a wide range of theoretical lenses, including but limited to social network (Dhanasai \& Parkhe, 2006; Dyer, 1996a, 1996b), innovation ecosystem (Hellström, Tsvetkova, Gustafsson, \& Wikström, 2015), organization design (Fjeldstad et al., 2012; Foss \& Weber, 2016; Gulati, Puranam, et al., 2012; Tantalo \& Priem, 2016) and stakeholder (Bridoux \& Stoelhorst, 2014, 2016). For example, (Dyer \& Singh, 1998) coin that inter-firm relationships are sources of competitive advantage and should be a distinctive unit of analysis. (Gulati, Wohlgezogen, et al., 2012) put forward the importance of both cooperation and coordination, the two facets of collaboration, in resolving issues in the design, formation, and post-formation of multi-organizational relationships. Last but not least, (Alstyne et al., 2016) argue that strategies to expand value for the entire ecosystem has dominated in the new business environment. In a word, the joint efforts among multiple firms are critical for the benefits of the individual firm as well as firms connected with each other in a system.

As an attempt to consolidate these lines of inquiry on value co-creation, this paper makes a painstaking investigation for the fundamental concepts of value co-creation by juxtaposing received literature in marketing that addresses value co-creation and related work in strategy field to illuminate value co-creation in value-based strategy and draw out the elements accordingly. From examining related literature in business-to-business marketing (Galvagno \& Dalli, 2014; Kohtamäki \& Rajala, 2016; Ranjan \& Read, 2016) and strategy, we define value co-creation strategy as "the unity among a group of autonomous organizations in the collaboration system to form a loosely coupled organic system that aims at pursuing a shared goal, which requires the joint efforts of these firms, so that economic and non-economic benefits are generated for both the collective and individual firm." Our definition incorporates multi-organizational relationships and value co-creation concepts to accommodate further research of value co-creation in the multi-organizational collaboration context.

\section{Producing and Assessing Collaborative Value Based on a Framework of Value Co-creation}

As aforementioned that the key to successful multi-organizational collaborations lies in whether these organizations jointly create value in the first place, therefore a tentative research framework, along with the corresponding research propositions, are introduced hereafter with value co-creation lens. 


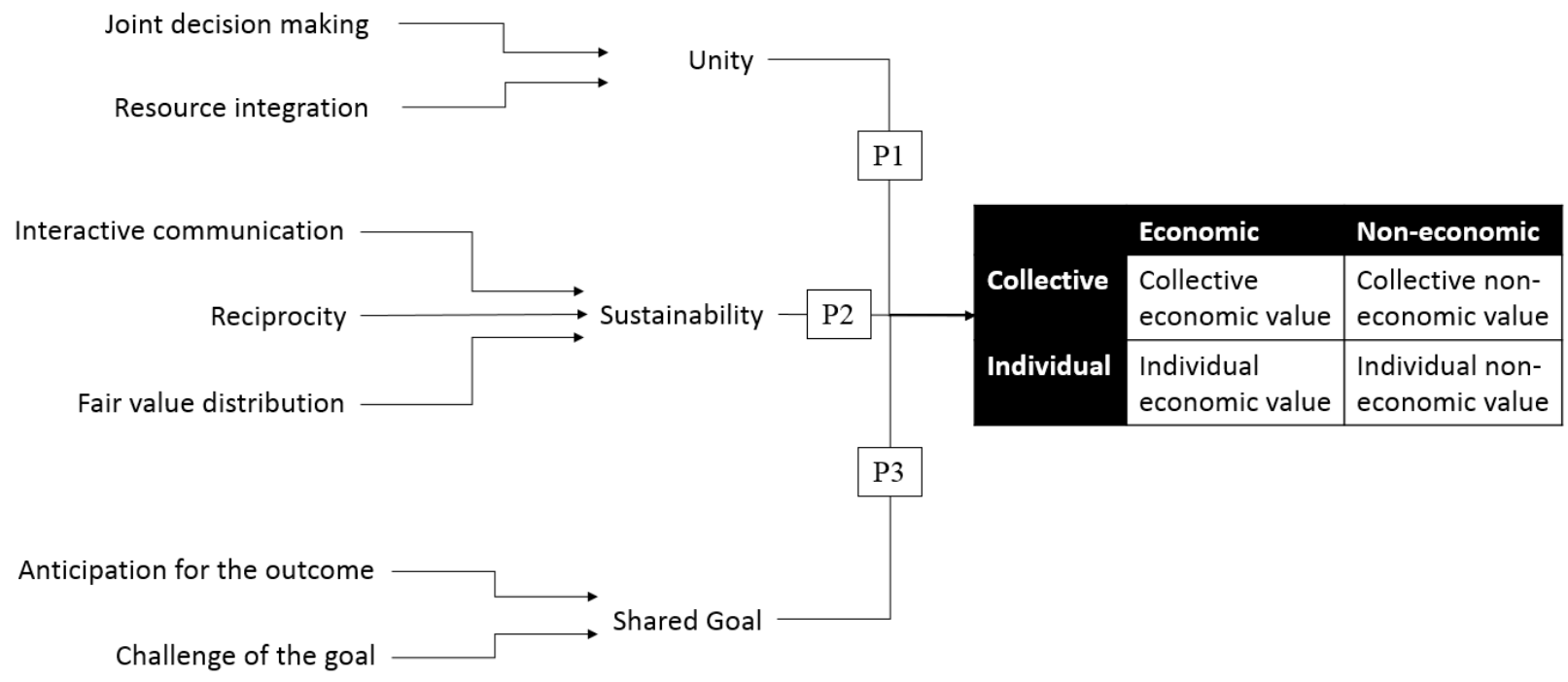

Figure 1. Overview of proposed relationships

\subsection{Forms of Value}

Essentially, from the value co-creation perspective, value is extended from conventional exchange value to encompass that of value generated from user experience (Marcos-Cuevas et al., 2016; Ramírez, 1999; Ranjan \& Read, 2016). In the same vein, the value created by multiple organizations in the system goes beyond conventional monetarily value to include a variety of others, such as social capital, organizational learning, and communication (Koschmann et al., 2012; Xia et al., 2012). To account for different types of value created by multi-organizational collaborations, we categorize the different types of value according to two dimensions: level and type. Level refers to whether the performance can be attributed to the collective level or the individual participant in the value co-creating system. For example, the emergence of a new market (Pitelis, 2012) is a system level value that would bring new opportunities for all organizations in the collaboration system in the system. This dimension highlights the fact that activities in the co-creation system are meant to bring benefits to the system as well as the individual participant (Ramaswamy \& Gouillart, 2010). Take Toyota Keiretsu, a high-performing and sustaining value co-creation system (Wilhelm \& Kohlbacher, 2011), for example (Aoki \& Lennerfors, 2013; Dyer, 1996b; Dyer \& Singh, 1998; Wilhelm \& Kohlbacher, 2011), the interactions make Toyota cars, the embodiment of their collaborations, highly successful in the global automobile industry, thus creating system-level values. Meanwhile, individual participant in the system gain profits and learn from interactions with the hub firm, Toyota, or other suppliers in the system (Dyer \& Nobeoka, 2000). In Toyota Keiretsu, to develop complete brake systems, the brake divisions of Toyota and three of Toyota's suppliers jointly formed a new company, Advics, so that a $30 \%$ cost reduction in the antilock system was made possible (Aoki \& Lennerfors, 2013). The improved product design and purchasing effectively enhanced the competitiveness of Noah and Voxy cars, brining benefits for the entire Kereitsu, and, at the same time, the establishment of Advics was a sort of value for the firm itself.

The other dimension -- type --- depicts whether the created value can be measured in monetary form, as it is important to understand that both economic and non-economic exchanges are included in value exchanges (Kohtamäki \& Rajala, 2016). Take profit (Lambert \& Enz, 2012) as an example, it can be precisely calculated from the financial statements for individual firm and is explicated evaluated by currency, and thus belongs to the economic value category. Besides, patent, an emerging indicator of innovation performance (Odasso, Scellato, \& Ughetto, 2015; Ransbotham \& Mitra, 2010; Vakili, 2016; Wang, Lo, \& Liao, 2015), and the valuation has evolved from simply counting the number of patents a firm has (Cockburn \& Griliches, 1988) to calculating how many times the patents are cited, to sophisticated patent valuation nowadays (Odasso et al., 2015; Ransbotham \& Mitra, 2010; Wang et al., 2015). Recent scholarly attempt in adopting patent pool as collaboration performance measurement (Vakili, 2016) has legitimized the inclusion of patents as economic value for co-creating organizations in the collaboration system. Besides economic value, non-economic value, which is difficult to be measured by numbers or currency, also plays an important role in the co-creating system. Without the knowledge spill-overs among multiple members in the 
Toyota Keiretsu, innovation speed would have been hampered. Likewise, the relationships among members and collective decision-making promote a variety of non-economic value, such as social capital, learning and others.

As shown in the topologies, quadrant 1 , intersect of non-economic and system level, represents the qualitative collective outcomes such as new market, new business model, new standard (Pitelis, 2012; Xia et al., 2012). Quadrant 2, intersect of economic and system level value, indicate to quantitative collective value like market size (Chang \& Chen, 2016). Quadrant 3, intersect of individual level and economic value, depicts the quantitative value, such as profits, patents, and the like, that belong to individual member in the co-creating system. Lastly, in quadrant 4 , intersect of individual and non-economic value, highlights the qualitative benefits for individual participant, such as insights, knowledge, organizational learning, social capital, and the like (Aoki \& Lennerfors, 2013; Ramaswamy \& Gouillart, 2010; Wilhelm \& Kohlbacher, 2011; Xia et al., 2012). This topology accentuates the fact that successful collaborations bring a wide variety of value to the collective as well as the individual participant, and also reflects that multi-organizational collaboration performance needs to be measured from different perspectives. It is noteworthy that in a value co-creating system, different types of value are created simultaneously (Kohtamäki \& Rajala, 2016). As emphasized in the beginning of this paper about the research purpose of delving into value creation, the accentuation of both-and relationship, rather than either-or, among these types of value is a manifestation of the research purpose.

To highlight multi-organizational collaborations and specific actions in achieving value co-creation, we employ the dimensions of value co-creation - linking, materializing, and institutionalizing (Marcos-Cuevas et al., 2016) categorized by (Marcos-Cuevas et al., 2016) and transform them to match the multi-organization collaboration context to develop a multi-organizational value co-creation framework, shown as Figure 1. The first overarching dimension, linking, denotes the facilitating connections and mobilizing the network of firms by sharing and circulating knowledge. Juxtaposing the definition and the multi-organizational context, such as the Toyota Keiretsu, we adopt unity to denote elements that bind multiple organizations in the system. These mechanisms ideally take place on a collaborative basis, and include joining efforts and sharing knowledge and resources both about value offerings (Normann \& Ramirez, 1993) and multilateral relationships. The second dimension, materializing, is defined as "operational practices tightly related to the emergence of co-created offerings" ((Marcos-Cuevas et al., 2016), p.100), and imprints the notion of sustainability in the multi-organizational context. Sustainability depicts system-level mechanisms tightly related to strengthening the relationships and forming virtuous circles for the viability of the value co-creation system. The last dimension, institutionalizing, means continuous coordination, and corresponds to shared goal in the multi-organizational context. Shared goal is embedded across unity enhancement and sustainability generation by functioning as a governance mechanism to guide collaborations. To elucidate, we group different types of actions into unity enhancement, sustainability generation, and shared goal for the multi-organizational context.

\subsection{Binding Multiple Organizations-Unity}

Unity (Albers, Wohlgezogen, \& Zajac, 2016; Mahoney \& Qian, 2013; Marcos-Cuevas et al., 2016; Metcalf \& Urwick, 2004; Penrose, 2008; Pitelis, 2012; Ramírez, 1999) is the state when multiple organizations in the collaboration system in the value co-creation system are tightly connected to each other so that they behave in a coherent manner. The conventional wisdom by Follett in the 1940's (Metcalf \& Urwick, 2004), who wrote, "the first test of business administration ... should be whether you have a business with all its parts so co-ordinated, so moving together in their closely knit and adjusting activities, so linking, interlocking, interrelating, that they make a working unit, ((Metcalf \& Urwick, 2004 p.71)" is even more prominent in the business nowadays. With the seemly boundary-less architecture of business networks (Gulati, Puranam, et al., 2012; Marcos-Cuevas et al., 2016), how multiple organizations function as different parts of the meta-organization to become "a functional whole or integrative unity ((Metcalf \& Urwick, 2004 p.71)" is a challenge that transcend firm boundary to the system level (Gulati, Puranam, et al., 2012; Penrose, 2008). In another word, when unity is present, resources and capabilities from the diverse organizations in the collaboration system can be pulled out from individual organizations and be integrated, so that different types of value can be achieved.

Two key mechanisms are salient for multiple organizations to achieve unity: joint decision-making and resource integrations. Firstly, joint decision making (Dyer \& Singh, 1998) is an essential embodiment of unity. Since the roles of organizations in the collaboration system in a value co-creating system are likely to be diverse and complicated, there inherently exist differences in a wide range of things, including organizational goals, resources, capabilities, organizational routines, and even conflicting interests that may entail reverse selection (Bridoux \& Stoelhorst, 2014, 2016). As such, the processes of negotiating towards shared decision is helpful to enhance pre-decision multi-lateral 
understanding, understand the necessary compromises and endowments, and thus to make post-decision executions more fluent (Dyer \& Nobeoka, 2000). Of course joint decision-making involves intensive discussions and risk of departure (Branstetter \& Sakakibara, 2002; Olk \& Young, 1997), but these processes are crucial for forming multi-organizational unity because during the decision-making process, organizations have the chance to know each other better, thus consolidate the relationships. Although it takes much more time to reach consensus for multiple organizations, it helps participating organizations to understand the issue and understand other organizations' concerns, and thus allow them to learn from others or gain the potential to access resources. In another word, the accumulation of mutual understanding, knowledge sharing and learning exceeds the higher communication cost to obtain decision consensus. With joint decision making, organizations in the collaboration system can pool their strengths and complement each other to realize different kinds of value. Therefore, we propose:

Proposition la: Joint decision making among multiple organizations enhance the non-economic collaboration value, such as knowledge sharing and mutual understanding, thus individual organizations as well as the value co-creating system gain benefit.

Besides joint decision-making, resource integration among organizations positively allow value co-creating organizations in the collaboration system to make tangible contributions to the group and passively lock the organization in the system. On the one hand, when a participating organization contributes resources to the collective, it is more likely to stay in the system and try to realize the anticipated value (Sirmon, Hitt, \& Ireland, 2007). On the other hand, when the participant receives complementary resources from other organizations in the collaboration system, it may become reliant on the system so that these organizations interlocked (Metcalf \& Urwick, 2004) and integration value creation (Sirmon, Hitt, Ireland, \& Gilbert, 2010). Therefore, we propose:

Proposition 1b: The integration of resources beyond the organizational boundaries among multiple organizations facilitate shortening time to market, reduce resource redundancy, lower cost, and others, so to benefit individual organizations and the value co-creating system.

\subsection{Keeping Multiple Organizations in the Relationship-Sustainability}

Sustainability refers to the state that relationships among organizations in the collaboration system in the value co-creating system are tight and steady and that there are positive feedbacks among the participating organizations so that they stay in the system and even attract other organizations to join. Sustainability is the transformation of materializing in value co-creation with customers to the context of multi-organization collaborations. In the general value co-creation context, this dimension accentuates what firms and customers do together to generate the product or service that fulfill the intrinsic need, implying the working-together of multiple organizations in the multi-organizational collaboration context that leads to "togetherness" of the system. So we map materializing with sustainability. The duration of the value co-creating system is dependent upon the task instead of actual time. For example, a Keiretsu lasts as long as the end brand stays in the market (Aoki \& Lennerfors, 2013; Dyer \& Nobeoka, 2000), but a R\&D consortium is effective only until the target technology or product is completed (Branstetter \& Sakakibara, 2002; Olk \& Young, 1997). Taking the nature of the task into account, sustainability implies the viability and growth of the system until its termination due to the accomplishment of the ultimate goals.

In order to continuously bring out the desired offerings among organizations, we argue that three major mechanisms are salient: interactive communication, reciprocity, and fair value distribution. Firstly, communication is critical for multiple organizations to enhance the collaboration performance (Koschmann et al., 2012), we further extend the communication to interactive communications to accentuate the multi-directional characteristic to accommodate the multi-organizational context. Since organizations in the value co-creating system are linked together by relational means rather than hierarchical or authoritarian mechanisms that they share equal status with each other and have no obligation to respond to commends by other organizations, interactive communication becomes exceptionally critical to make organizations understand each other thus to decide on whether to respond or act upon the need of other organizations. Besides, without interactive communications, organizations may not understand the need of other organizations, and waste time and energy working on projects or research and development in self-interested search that lead to less success. On the contrary, when organizations learn about each other, understand the strength and weakness of each other, and more importantly discover feasible opportunities to enhance cooperation to achieve economic gains, such as co-innovate. In another word, interactive communications enable the exchange of knowledge and enhance the connections, and facilitate the formation of social capital among organizations, thus consolidation the foundation for collaborations. In this vein, we propose:

Proposition 2a: Interactive communications among multiple organizations facilitate the co-creation of economic and non-economic value, and benefit individual organizations as well as the collective collaboration as a whole. 
Secondly, reciprocity (Breidbach \& Maglio, 2016; Dyer \& Singh, 1998) indicates positive rewards for the effort-paying organizations as well as penalty for adverse behavior. Positively speaking, reciprocity impels that those who receive favor will return good deeds to those favor-givers, making the givers willing to contribute next time. In the long run, reciprocity can induce continuous contribution of those resource or capability owners. In addition, it passively prevails against harmful conducts (Fonti et al., 2017).

In terms of forms of reciprocation, financial benefits (Chang \& Chen, 2016) or establishment of trust and good relationships among organizations in the collaboration system (Breidbach \& Maglio, 2016) are possible, thus generating a variety of value. Moreover, reciprocity effectively binds "good players" in the system, and thus enhances the value of the co-creating system.

Proposition 2b: Reciprocity among the collaborating organizations generate both economic and non-economic value so that individual organizations and the system as a whole can benefit.

Thirdly, the co-created value should be distributed not evenly but fairly according to the efforts of the organizations (Dyer \& Singh, 1998; Ramaswamy \& Gouillart, 2010). On the one hand, for organizations that pay attention to the needs of the system and invest their resources to the collective good get what they deserve, urging them to keep positive feedback loop. This means that organizations in the collaboration system are willing to contribute to the collective good when they know they will receive fair value from the system (Dyer \& Singh, 1998). On the other hand, free-riding (Fonti et al., 2017), lack of effort or not doing one's best, is punished, and those who free ride might leave the system. In a word, these three mechanisms are critical for keeping effort-paying organizations in the system, building up multi-organizational relationships, generating self-enforcing atmosphere, and ultimately allowing the co-creating system to last.

Proposition 2c: Fair value distribution among the organizations in the collaboration system facilitates co-creating economic and non-economic value in the individual and collective levels.

\subsection{Producing Coherently Among Multiple Organizations-Shared Goal}

As denoted in the literature review and multi-organizational value co-creation definition, participants are not necessarily bounded to authoritarian relationships (Gulati, Puranam, et al., 2012), resembling the relationships among the focal firm and its customers when co-creating value with customers (Prahalad \& Ramaswamy, 2004; Vargo et al., 2008). As a reflection to such non-authoritarian governance, relational mechanisms (Gulati, Puranam, et al., 2012; Lavie, Haunschild, \& Khanna, 2012) have been viewed as major device (Dyer, 1996a) in steering successful multi-organizational collaborations (Albers et al., 2016).

However, in the value co-creating system, we argue that shared goals (Fonti et al., 2017; Lindenberg \& Foss, 2011; Xia et al., 2012) dominant over relationships in replacing authoritarian governance. For the first reason, radical technology changes and intensified global competition force organizations to be more agile in responding to business changes, and switching partners becomes necessary for survival. Besides, the pressure to effectively reduce cost makes global sourcing, continuous search for partners who can provide the same quality in ever lower prices, a means for organizations to compete that even Toyota had to reform its Keiretsu to meet the severe demand from the business environment (Aoki \& Lennerfors, 2013). In a word, relationships are difficult to establish and even harder to maintain in this turbulent and unpredictable business environment nowadays.

Under this circumstances, shared goals, on the other hand, are more achievable and effective in enhancing multi-organization value co-creation. Since shared goals call for the contributions from all organizations in the collaboration system in the system (Fonti et al., 2017), they are more powerful than relationships in binding the organizations together. Besides, shared goals can endure the test of time. If the value co-creation system has short-term goal, such as forming an industry standard (Xia et al., 2012), shared goals do not require long time to establish. Likewise, when there are long-standing partnerships, shared goals can change based on environmental changes. In short, in the value co-creation system, shared goals that are more flexible and more resistant to the rapid changing world act as governance mechanisms that draw psychological commitments and physical investments of participating firms in the business system.

When it comes to how shared goals function as the governance mechanism, one prominent feature is the anticipation on the outcome. When the organization has high anticipations for the outcome, it is more likely to stick with the goals and endure certain extend of compromise, which is often needed in multi-party collaborations, when such compromise (Reypens, Lievens, \& Blazevic, 2016) is necessary in achieving the shared goal. Also, when the anticipated outcomes match the needs of the participating organizations, organizations are more willing to devote necessary resources (Lindenberg \& Foss, 2011), and cooperate with other partners, thus achieve value co-creation. 
Proposition 3a: Organizations in the collaboration system' anticipations of the shared goal facilitate co-creating economic and non-economic value in the individual and collective levels.

Complementing the motivating effects of anticipation is the extent of challenge for achieving the shared goal, which has both active and passive impact on collaboration's major impediment - free-ride (Fonti et al., 2017). Actively, challenging goals inform organizations in the collaboration system to pay more attention and prepare for contributing more; passively, challenging goals will obstruct those who lack either ability or willingness in striving for the goal. Although the passive impact may leave latent organizations in the collaboration system in hesitation, it induces in-depth consideration instead of tempt fate. Therefore, the extent of challenge of the shared goal incur careful consideration before joining the value co-creating system.

It would be true that comparative parties are also more capable of cheating their partners since the partners may not be able to detect. But, again, challenging goals force more participant devotion so that the consequences of cheating or shrinking, late deliveries or lack of performance, are easier to be spotted. Furthermore, challenging goals can draw more attention from the organizations in the collaboration system, effectively link them together, which is an overarching dimension in value co-creation (Marcos-Cuevas et al., 2016).

Proposition 3b: The extent of challenge in achieving the shared goal facilitates co-creating economic and non-economic value in the individual and collective levels.

\section{Discussion and Future Research}

In order to provide a feasible resolution to the on-going debates on collaboration performance, this paper proposes a research framework that accentuates joint value creation among multiple organizations that form a system, and particularly denotes the multi-lateral nature in such value co-creating system. Theoretically, we consolidate ideas from relational view, multi-organizational collaborations, and vale co-creation paradigm to form the proposed research framework, and draw propositions accordingly. Practically, several cases are adopted to assist clarifying the arguments as well as to exemplify. As a result, the research framework and propositions are meant to be comprehensive and overarching to induce further investigations.

Critical to these avenues of future research is to temporarily put aside value capture concern, because this research calls for significantly emphasis on how different types of value are created, as a fresh approach to unravel collaboration performance. In another word, this paper admits the existence of opportunism, but choses to weaken its impact (Foss \& Weber, 2016) so that major efforts can be put on putting value creation in the center stage. Thus, as this paper attempts to provide a comprehensive framework, there are three major avenues to further this line of inquiries: multi-level inspections, longitudinal observations on the dynamics, and empirical validations.

First of all, from the structural perspective, multi-level investigations are essential and potentially fruitful avenues of research. As highlighted, more than organizations in the collaboration system take part in value co-creation, so investigations into how the focal organization interacts with all other organizations to generate different types of value are necessary. In this line of inquiry, direct relationships, indirect ones and their combinations affect the collaborative performance should be taken into consideration (Kohtamäki \& Rajala, 2016), since they are likely to have different impact on value co-creation. Furthermore, every proposed construct can be further delved into from the individual-others, individual-system, and system-system levels. Therefore, interactions between individual organizations in the collaboration system and the overall system, such as goal alignment and departure decisions, affect whether and how value is co-created, and thus call for further investigations. Finally, as competitions elevated to the system level in the value co-creation era, the dynamics between different value co-creating systems also call for further research. For instance, how the the pan-iTunes system, comprising the APP developers and content providers, competes with the Pan-Android system with respect to unity, sustainability, shared goal, and co-created value.

Secondly, longitudinal studies are expected to compliment the proposed framework. In order to elucidate the joint efforts in the collaborative system, this paper deviates towards cross-sectional analysis. Although the inclination is a necessary choice to make our statements clear, longitudinal observations of the value co-creating system are certainly fundamental to gain insight in critical issues, such as how unity and shared goals emerge and evolve, whether different types of value are achieved chronologically, and so on. Further penetration may lead to understanding what and how organizations in the collaboration system make decisions on stay in or leave (Olk \& Young, 1997), and how the system can be enhanced or fade away (Tomasello et al., 2016). To put it in another word, one crucial avenue for future work relates to delving into how the proposed constructs and the value co-creation system as a whole start to exist and later evolve over time, and finding out what factors make them prosper or shrink. 
The forth future research concerns whether and how each element in the proposed framework has different importance in the emergence of multi-organizational collaborations. Since the focus of this paper lies in finding key elements that make multiple organizations work together to successfully achieve the shared goal, it leaves whether certain element plays more significant role than others undiscussed. Besides, it is possible that the importance of the elements varies under different circumstances. For instance, in the initial stage of the collaboration system, the attractiveness of the shared goal might be more important than sustainability. In short, difference of importance as well as conditions that incur such difference require further investigations.

Last but not least, validation of the proposed framework requires both quantitative and qualitative work so that the variables can be measured. For example, economic values need to be measured with numbers while non-economic values shall be analyzed qualitatively. Besides, both unity and sustainability shall be analyzed with mixed methodologies.

Aforementioned are three overarching directions for future research that are essential for enhancing understanding about value co-creation in the practical and theoretical manner.

\section{Conclusion}

The advantages of multi-organizational collaborations have been extensively discussed in received literature, without conclusive results on what value the collective efforts bring. This paper adopts the value co-creation paradigm, which has emerged and growingly gained attention in marketing, service science, and technology management fields for about a decade (Alves et al., 2016; Galvagno \& Dalli, 2014; Ind \& Coates, 2013; Prahalad \& Ramaswamy, 2004; Ranjan \& Read, 2016; Vargo et al., 2008) to accentuate the diverse benefits generated from the joint value creation among multiple organizations in the collaboration system. The idea of value co-creation, although has not yet been widely discussed in general management and strategy field, emphasizes joining the efforts of suppliers and consumers in creating values from using the product or services, and is suitable to be applied in the multi-organizational collaboration context. In this vein, this paper proposes research framework that sheds light on the following: (1) all the organizations who take part in the collaborations should be evaluated collectively as an integrated system; (2) Multi-organizational collaboration performance is decomposed into four types, according to whether it is economic value or non-economic value and whether it benefits individual organizations in the collaboration system or the collective system; and (3) three overarching dimensions, namely unity, sustainability, and shared goal, are proposed to correspond to the overarching dimensions in value co-creation paradigm.

By focusing on various kinds of value, co-creation, and multi-lateral relationships, this research has contributed to theory and practice. With respect to theory, our first contribution lies in the attempt to resolve the on-going debates in strategy by innovatively adopting value co-creation paradigm. Indeed, future empirical validations are necessary to test the proposed arguments, but the step forward taken by this research inherently is a step forward in strategy studies, thus should be positively recognized. Secondly, performance is refreshingly gauged by new dimensions as opposed to simply focusing on economic profits. Our multi-dimensional examination of value aligns with recent management studies, such as (Xia et al., 2012), and is more comprehensive by incorporating both conventional and novel perspectives that consider both collective and individual levels and economic and non-economic types. Lastly, this paper excavates from literature to denote three major variables, and explains how they affect collaboration value. Particularly, the replacement of shared goal for formal monitoring to be the governing mechanism is a strong and daring argument that extends the work of (Gulati, Puranam, et al., 2012) by attending to governance in non-authoritarian relationships.

When it comes to contributions to practice, we would like to lay particular stress on the fact that value co-creation has existed in practice for a very long time, such as the Japanese keiretsu, so the major contribution of this paper is to arouse attention to such enduring practice that has been proven successful. On the other hand, the proposed framework provides a feasible direction for managers to orchestrate a value co-creating system with their partners. 


\section{References}

Albers, S., Wohlgezogen, F., \& Zajac, E.J. (2016). Strategic Alliance Structures: An Organization Design Perspective. Journal of Management, 42(3), 582-614. https://doi.org/10.1177/0149206313488209

Alstyne, M.W.V., Parker, G.G., \& Choudary, S.P. (2016). Pipelines, Platforms, and the New Rules of Strategy. Harvard Business Review, 94(4), 54-62.

Alves, H., Fernandes, C., \& Raposo, M. (2016). Value co-creation: Concept and contexts of application and study. Journal of Business Research, 69(5), 1626-1633. https://doi.org/10.1016/j.jbusres.2015.10.029

Aoki, K., \& Lennerfors, T.T. (2013). The New, Improved Keiretsu. Harvard Business Review, 91(9), $109-113$.

Brandenburger, A.M., \& Stuart, H.W. (1996). Value-based Business Strategy. Journal of Economics \& Management Strategy, 5(1), 5-24. https://doi.org/10.1111/j.1430-9134.1996.00005.x

Branstetter, L.G., \& Sakakibara, M. (2002). When Do Research Consortia Work Well and Why? Evidence from Japanese Panel Data. American Economic Review, 92(1), 143-159. https://doi.org/10.1257/000282802760015649

Breidbach, C.F., \& Maglio, P.P. (2016). Technology-enabled value co-creation: An empirical analysis of actors, resources, and practices. Industrial Marketing Management, 56, 73-85. https://doi.org/10.1016/j.indmarman.2016.03.011

Bridoux, F., \& Stoelhorst, J.W. (2014). Microfoundations for stakeholder theory: Managing stakeholders with heterogeneous motives. Strategic Management Journal, 35(1), 107-125. https://doi.org/10.1002/smj.2089

Bridoux, F., \& Stoelhorst, J.W. (2016). Stakeholder Relationships and Social Welfare: A Behavioral Theory of Contributions to Joint Value Creation. Academy of Management Review, 41(2), 229-251. https://doi.org/10.5465/amr.2013.0475

Chang, S.C., \& Chen, I.F. (2016). Value added or tunneling? Evidence from new product announcements by Taiwanese business groups. Journal of Management \& Organization, 22(5), 623-641. https://doi.org/10.1017/jmo.2015.60

Chatain, O. (2011). Value creation, competition, and performance in buyer-supplier relationships. Strategic Management Journal, 32(1), 76-102. https://doi.org/10.1002/smj.864

Chatain, O., \& Zemsky, P. (2011). Value creation and value capture with frictions. Strategic Management Journal, 32(11), 1206-1231. https://doi.org/10.1002/smj.939

Cockburn, I., \& Griliches, Z. (1988). Industry Effects and Appropriability Measures in the Stock Market's Valuation of R\&D and Patents. American Economic Review, 78(2), 419.

Dhanasai, C., \& Parkhe, A. (2006). Orchestrating Innovation Networks. The Academy of Management Review, 31(3), 659-669. https://doi.org/10.5465/amr.2006.21318923

Dyer, J.H. (1996a). Does Governance Matter? Keiretsu Alliances and Asset Specificity As Sources of Japanese Competitive Advantage. Organization Science, 7(6), 649-666. https://doi.org/10.1287/orsc.7.6.649

Dyer, J.H. (1996b). Specialized Supplier Networks as a Source of Competitive Advantage: Evidence from the Auto Industry. Strategic Management $\quad$ Journal, $271-291$. https://doi.org/10.1002/(SICI)1097-0266(199604)17:4<271::AID-SMJ807>3.0.CO;2-Y

Dyer, J.H., \& Nobeoka, K. (2000). Creating and Managing a High-Performance Knowledge-Sharing Network: The Toyota Case. Strategic Management Journal, $345-367$. https://doi.org/10.1002/(SICI)1097-0266(200003)21:3<345::AID-SMJ96>3.0.CO;2-N

Dyer, J.H., \& Singh, H. (1998). The Relational View: Cooperative Strategy and Sources of Interorganizational Competitive Advantage. The Academy of Management Review, 23(4), 660-679. https://doi.org/10.2307/259056

Fjeldstad, Ø.D., Snow, C.C., Miles, R.E., \& Lettl, C. (2012). The architecture of collaboration. Strategic Management Journal, 33(6), 734-750. https://doi.org/10.1002/smj.1968

Fonti, F., Maoret, M., \& Whitbred, R. (2017). Free-riding in multi-party alliances: The role of perceived alliance effectiveness and peers' collaboration in a research consortium. Strategic Management Journal, $38(2), 363-383$. https://doi.org/10.1002/smj.2470 
Foss, N.J., \& Weber, L. (2016). Moving Opportunism to the Back Seat: Bounded Rationality, Costly Conflict, and Hierarchical Forms Academy of Management Review, 4l(1), 61-79. https://doi.org/10.5465/amr.2014.0105

Galvagno, M., \& Dalli, D. (2014). Theory of value co-creation: a systematic literature review. Managing Service Quality: An International Journal, 24(6), 643-683. https://doi.org/10.1108/MSQ-09-2013-0187

Gulati, R., Puranam, P., \& Tushman, M. (2012). Meta-organization design: Rethinking design in interorganizational and community contexts. Strategic Management Journal, 33(6), 571-586. https://doi.org/10.1002/smj.1975

Gulati, R., Wohlgezogen, F., \& Zhelyazkov, P. (2012). The Two Facets of Collaboration: Cooperation and Coordination in Strategic Alliances. The Academy of Management Annals, 6(1), 531-583. https://doi.org/10.1080/19416520.2012.691646

Hellström, M., Tsvetkova, A., Gustafsson, M., \& Wikström, K. (2015). Collaboration mechanisms for business models in distributed energy ecosystems. Journal of Cleaner Production, 102, 226-236. https://doi.org/10.1016/j.jclepro.2015.04.128

Ind, N., \& Coates, N. (2013). The meanings of co-creation. European Business Review, 25(1), 86-95. https://doi.org/10.1108/09555341311287754

Kohtamäki, M., \& Rajala, R. (2016). Theory and practice of value co-creation in B2B systems. Industrial Marketing Management, 56, 4-13. https://doi.org/10.1016/j.indmarman.2016.05.027

Koschmann, M.A., Kuhn, T.R., \& Pfarrer, M.D. (2012). A Communicative Framework of Value in Cross-Sector Partnerships. Academy of Management Review, 37(3), 332-354. https://doi.org/10.5465/amr.2010.0314

Lambert, D.M., \& Enz, M.G. (2012). Managing and measuring value co-creation in business-to-business relationships. Journal of Marketing Management, 28(13-14), 1588-1625. https://doi.org/10.1080/0267257X.2012.736877

Lavie, D., Haunschild, P.R., \& Khanna, P. (2012). Organizational differences, relational mechanisms, and alliance performance. Strategic Management Journal, 33(13), 1453-1479. https://doi.org/10.1002/smj.1987

Lindenberg, S., \& Foss, N.J. (2011). Managing Joint Production Motivation: The Role of Goal Framing and Governance Mechanisms. Academy of Management Review, 36(3), 500-525. https://doi.org/10.5465/AMR.2011.61031808

Mahoney, J.T., \& Qian, L. (2013). Market frictions as building blocks of an organizational economics approach to strategic management. Strategic Management Journal, 34(9), 1019-1041. https://doi.org/10.1002/smj.2056

Marcos-Cuevas, J., Nätti, S., Palo, T., \& Baumann, J. (2016). Value co-creation practices and capabilities: Sustained purposeful engagement across B2B systems. Industrial Marketing Management, 56, 97-107. https://doi.org/10.1016/j.indmarman.2016.03.012

Metcalf, H.C., \& Urwick, L. (2004). Dynamic administration: the collected papers of Mary Parker Follett: Routledge.

Mindruta, D. (2013). Value creation in university-firm research collaborations: A matching approach. Strategic Management Journal, 34(6), 644-665. https://doi.org/10.1002/smj.2036

Möller, K., \& Svahn, S. (2006). Role of Knowledge in Value Creation in Business Nets*. Journal of Management Studies, 43(5), 985-1007. https://doi.org/10.1111/j.1467-6486.2006.00626.x

Normann, R., \& Ramirez, R. (1993). From value chain to value constellation: Designing interactive strategy. Harvard Business Review, 71(4), 65-77.

Obloj, T., \& Zemsky, P. (2015). Value creation and value capture under moral hazard: Exploring the micro-foundations of buyer-supplier relationships. Strategic Management Journal, 36(8), 1146-1163. https://doi.org/10.1002/smj.2271

Odasso, C., Scellato, G., \& Ughetto, E. (2015). Selling patents at auction: an empirical analysis of patent value. Industrial \& Corporate Change, 24(2), 417-438. https://doi.org/10.1093/icc/dtu015

Olk, P., \& Young, C. (1997). Why Members Stay in or Leave an R\&D Consortium: Performance and Conditions of Membership as Determinants of Continuity. Strategic Management Journal, 18(11), 855-877.

Payne, A.F., Storbacka, K., \& Frow, P. (2008). Managing the co-creation of value. Journal of the Academy of Marketing Science, 36(1), 83-96. https://doi.org/10.1007/s11747-007-0070-0 
Penrose, E. (2008). Strategy/Organization and the Metamorphosis of the Large Firm. Organization Studies, 29(8-9), 1117-1124. https://doi.org/10.1177/0170840608096001

Pitelis, C.N. (2012). Clusters, entrepreneurial ecosystem co-creation, and appropriability: a conceptual framework. Industrial and Corporate Change, 21(6), 1359-1388. https://doi.org/10.1093/icc/dts008

Pitelis, C.N., \& Teece, D.J. (2009). The (new) nature and essence of the firm. European Management Review, 6(1), 5-15. https://doi.org/10.1057/emr.2009.1

Prahalad, C.K., \& Ramaswamy, V. (2004). The Future of Competition: Co-Creating Unique Value With Customers. Harvard Business Press.

Ramaswamy, V., \& Gouillart, F. (2010). Building the Co-Creative Enterprise. Harvard Business Review, 88(10), 100-109.

Ramaswamy, V., \& Ozcan, K. (2014). The co-creation paradigm. Stanford University Press.

Ramírez, R. (1999). Value Co-Production: Intellectual Origins and Implications for Practice and Research. Strategic Management Journal, $20(1), \quad 49-65$. https://doi.org/10.1002/(SICI)1097-0266(199901)20:1<49::AID-SMJ20>3.0.CO;2-2

Ranjan, K.R., \& Read, S. (2016). Value co-creation: concept and measurement. Journal of the Academy of Marketing Science, 44(3), 290-315. https://doi.org/10.1007/s11747-014-0397-2

Ransbotham, S., \& Mitra, S. (2010). Target Age and the Acquisition of Innovation in High-Technology Industries. Management Science, 56(11), 2076-2093. https://doi.org/10.1287/mnsc.1100.1223

Reypens, C., Lievens, A., \& Blazevic, V. (2016). Leveraging value in multi-stakeholder innovation networks: A process framework for value co-creation and capture. Industrial Marketing Management, 56, 40-50. https://doi.org/10.1016/j.indmarman.2016.03.005

Sirmon, D.G., Hitt, M.A., \& Ireland, R.D. (2007). Managing Firm Resources in Dynamic Environments to Create Value: Looking inside the Black Box. Academy of Management Review, 32(1), 273-292. https://doi.org/10.2307/20159292

Sirmon, D.G., Hitt, M.A., Ireland, R.D., \& Gilbert, B.A. (2010). Resource Orchestration to Create Competitive Advantage: Breadth, Depth, and Life Cycle Effects. Journal of Management, 37(5), 1390-1412. https://doi.org/10.1177/0149206310385695

Tantalo, C., \& Priem, R.L. (2016). Value creation through stakeholder synergy. Strategic Management Journal, 37(2), 314-329. https://doi.org/10.1002/smj.2337

Tomasello, M.V., Napoletano, M., Garas, A., \& Schweitzer, F. (2016). The rise and fall of R\&D networks. Industrial and Corporate Change. https://doi.org/10.1093/icc/dtw041

Vakili, K. (2016). Collaborative Promotion of Technology Standards and the Impact on Innovation, Industry Structure, and Organizational Capabilities: Evidence from Modern Patent Pools. Organization Science, 27(6), 1504-1524. https://doi.org/10.1287/orsc.2016.1098

Vargo, S.L., \& Lusch, R.F. (2016). Institutions and axioms: an extension and update of service-dominant logic. Journal of the Academy of Marketing Science, 44(1), 5-23. https://doi.org/10.1007/s11747-015-0456-3

Vargo, S.L., Maglio, P.P., \& Akaka, M.A. (2008). On value and value co-creation: A service systems and service logic perspective. European Management Journal, 26(3), 145-152. https://doi.org/10.1016/j.emj.2008.04.003

Wang, M.Y., Lo, H.C., \& Liao, Y.Y. (2015). Knowledge Flow Determinants of Patent Value: Evidence from Taiwan and South Korea Biotechnology Patents. International Journal of Innovation \& Technology Management, 12(3), 1. https://doi.org/10.1142/S0219877015400040

Wilhelm, M.M., \& Kohlbacher, F. (2011). Co-opetition and knowledge co-creation in Japanese supplier-networks: The case of Toyota. Asian Business \& Management, 10(1), 66-86. https://doi.org/10.1057/abm.2010.31

Xia, M., Zhao, K., \& Mahoney, J.T. (2012). Enhancing value via cooperation: firms' process benefits from participation in a standard consortium. Industrial and Corporate Change, 21(3), 699-729. https://doi.org/10.1093/icc/dtr056 